\title{
Hyperlipidaemia is associated with increased insulin-mediated glucose metabolism, reduced fatty acid metabolism and normal blood pressure in transgenic mice overexpressing human apolipoprotein C1
}

\author{
S.J. Koopmans ${ }^{1}$, M.C.Jong ${ }^{2}$, I. Que ${ }^{3}$, V.E.H.Dahlmans ${ }^{2}$, H.Pijl ${ }^{4}$, J.K. Radder ${ }^{3}$, M.Frölich ${ }^{5}$, L.M.Havekes ${ }^{6}$ \\ ${ }^{1}$ ID TNO Animal Nutrition, Institute for Animal Science and Health, Lelystad, The Netherlands \\ ${ }^{2}$ TNO-Prevention and Health, Gaubins Laboratory, Leiden, The Netherlands \\ ${ }^{3}$ Department of Endocrinology, Leiden University Medical Center, Leiden, The Netherlands \\ ${ }^{4}$ Department of Internal Medicine, Leiden University Medical Center, Leiden, The Netherlands \\ ${ }^{5}$ Department of Clinical Chemistry, Leiden University Medical Center, Leiden, The Netherlands \\ ${ }^{6}$ Department of Internal Medicine and Cardiology, Leiden University Medical Center, Leiden, The Netherlands
}

\section{Abstract}

Aims/hypothesis. Insulin resistance for glucose metabolism is associated with hyperlipidaemia and high blood pressure. In this study we investigated the effect of primary hyperlipidaemia on basal and insulinmediated glucose and on non-esterified fatty acid (NEFA) metabolism and mean arterial pressure in hyperlipidaemic transgenic mice overexpressing apolipoprotein C1 (APOC1). Previous studies have shown that APOC1 transgenic mice develop hyperlipidaemia primarily because of an impaired hepatic uptake of very low density lipoprotein (VLDL).

Methods. Basal and hyperinsulinaemic $(6 \mathrm{mU}$. $\left.\mathrm{kg}^{-1} \cdot \mathrm{min}^{-1}\right)$, euglycaemic $(7 \mathrm{mmol} / \mathrm{l})$ clamps with 3 ${ }^{3} \mathrm{H}$-glucose or $9,10-{ }^{3} \mathrm{H}$-palmitic acid infusions and in situ freeze clamped tissue collection were carried out. Results. The APOC1 mice showed increased basal plasma cholesterol, triglyceride, NEFA and decreased glucose concentrations compared with wild-type mice $(7.0 \pm 1.2$ vs $1.6 \pm 0.1,9.1 \pm 2.3$ vs $0.6 \pm 0.1,1.9 \pm 0.2$ vs $0.9 \pm 0.1$ and $7.0 \pm 1.0 \mathrm{vs} 10.0 \pm 1.1 \mathrm{mmol} / \mathrm{l}$, respectively, $p<0.05)$. Basal whole body glucose clearance was increased twofold in APOC1 mice compared with wild-type mice $\left(18 \pm 2\right.$ vs $10 \pm 1 \mathrm{ml} \cdot \mathrm{kg}^{-1} \cdot \mathrm{min}^{-1}$, $p<0.05)$. Insulin-mediated whole body glucose uptake, glycolysis (generation of ${ }^{3} \mathrm{H}_{2} \mathrm{O}$ ) and glucose storage increased in APOC1 mice compared with wildtype mice $(339 \pm 28$ vs $200 \pm 11 ; 183 \pm 39$ vs $128 \pm 17$ and $156 \pm 44$ vs $72 \pm 17 \mu \mathrm{mol} \cdot \mathrm{kg}^{-1} \cdot \min ^{-1}, p<0.05$ respectively), corresponding with a twofold to threefold increase in skeletal muscle glycogenesis and de novo lipogenesis from $3-{ }^{3} \mathrm{H}$-glucose in skeletal muscle and adipose tissue $(p<0.05)$. Basal whole body NEFA clearance was decreased threefold in APOC1 mice compared with wild-type mice $(98 \pm 21$ vs $\left.314 \pm 88 \mathrm{ml} \cdot \mathrm{kg}^{-1} \cdot \mathrm{min}^{-1}, p<0.05\right)$. Insulin-mediated whole body NEFA uptake, NEFA oxidation (generation of ${ }^{3} \mathrm{H}_{2} \mathrm{O}$ ) and NEFA storage were lower in APOC 1 mice than in wild-type mice $(15 \pm 3$ vs $33 \pm 6$; $3 \pm 2$ vs $11 \pm 4$ and $12 \pm 2$ vs $22 \pm 4 \mu \mathrm{mol} \cdot \mathrm{kg}^{-1} \cdot \mathrm{min}^{-1}$, $p<0.05)$ in the face of higher plasma NEFA concentrations $(1.3 \pm 0.3$ vs $0.5 \pm 0.1 \mathrm{mmol} / 1, p<0.05)$, respectively. Mean arterial pressure and heart rate were similar in APOC1 vs wild-type mice $(82 \pm 4$ vs $85 \pm 3 \mathrm{~mm} \mathrm{Hg}$ and $459 \pm 14$ vs $484 \pm 11$ beats $\left.\cdot \mathrm{min}^{-1}\right)$. Conclusions/interpretation. 1) Hyperlipidaemic APOC1 mice show reduced NEFA and increased glucose metabolism under both basal and insulin-mediated conditions, suggesting an intrinsic defect in NEFA metabolism. Primary hyperlipidaemia alone in APOC1 mice does not lead to insulin resistance for glucose metabolism and high blood pressure. [Diabetologia (2001) 44: 437-443]

Keywords Hyperlipidaemia, APOC1, insulin resistance, insulin resistance syndrome, glucose, NEFA, triglycerides, cholesterol, lipoprotein, hypertension.
Received: 14 September 2000 and in revised form: 23 November 2000

Corresponding author: S.J. Koopmans PhD, ID TNO Animal Nutrition, P. O. Box 65, 8200 AB Lelystad, The Netherlands Abbreviations: APOC1, apolipoprotein C1; APOC3, apolipoprotein $\mathrm{C} 3$; HGP, hepatic glucose production.
Apolipoprotein (apo) $\mathrm{C} 1$ is a $6.6-\mathrm{kD}$ protein which is embedded in the outer shell of triglyceride-rich chylomicron, very low density lipoprotein (VLDL) and high density lipoprotein (HDL) particles. Recently we and others have investigated the role of apoC1 in lipoprotein metabolism with the generation of trans- 
genic mice overexpressing the human APOC1 gene $[1,2]$. High expressor APOC1 transgenic mice showed higher concentrations of VLDL-cholesterol and triglycerides because of an impaired hepatic uptake of VLDL [3]. High expressor APOC1 transgenic mice also had higher plasma concentrations of NEFA and lower abdominal adipose tissue stores (a $60 \%$ decrease compared with wild-type mice) and a complete deficiency of subcutaneous fat [4].

These results suggest that, in addition to the inhibitory role of apoC1 on hepatic remnant uptake, overexpression of apoC1 leads to reduced NEFA uptake and storage in peripheral tissues or reduced de novo lipogenesis from glucose or both. In the first case, the Randle cycle [5] predicts a negative interaction between (insulin-mediated) glucose and NEFA metabolism. In the case of impaired NEFA uptake and metabolism in APOC1 transgenic mice, glucose uptake and metabolism should be higher. On the other hand, if NEFA uptake and metabolism are higher in APOC1 transgenic mice, glucose uptake and metabolism should be lower. In addition, the Randle cycle is supposed to be operational in the so-called "insulin resistance syndrome". In the insulin resistance syndrome, a reduction in insulin-mediated glucose metabolism (i.e. insulin resistance) is strongly associated with hyperlipidaemia, increased plasma concentrations of NEFA and hypertension [6-9]. Because the APOC1 transgenic mouse is a model of primary hyperlipidaemia, we were able to study a possible causal relation between hyperlipidaemia and other aspects of the insulin resistance syndrome.

Therefore, we investigated the relation between plasma lipid concentrations, basal and insulin-mediated glucose and NEFA metabolism and blood pressure in APOC1 transgenic mice. For this purpose we carried out basal and hyperinsulinaemic euglycaemic clamp studies with $3-{ }^{3} \mathrm{H}$-glucose or $9,10-{ }^{3} \mathrm{H}$-palmitic acid infusions and measured mean arterial pressure in hyperlipidaemic APOC1 transgenic mice.

\section{Materials and methods}

\section{Animals and housing}

Transgenic mice with a high expression of the human APOC1 gene in the liver were generated as described previously and the characteristics of the mice were as indicated previously $[1$, $3]$. Both transgenic and wild-type (control) mice were subjected to a standard light (0600-1800 h) dark (1800-0600 h) cycle in an air-controlled room $\left(23^{\circ} \mathrm{C}\right)$ with free access to water and a standard mouse chow diet. The microbiological status of these mice was checked regularly by routine serological, bacteriological and histological procedures. Principles of laboratory animal care (NIH publication no.85-23, revised Iq85) were followed. The animal experiments were done in accordance with the regulations of Dutch law and the protocol was reviewed and approved by the local ethics committee for animal procedures of Leiden University.

\section{3- ${ }^{3} \mathrm{H}$-glucose or 9,10- ${ }^{3} \mathrm{H}$-palmitic acid infusions}

After a $6 \mathrm{~h}$ fast, both APOC1 transgenic $(n=20)$ and control $(n=20)$ mice were anaesthetised with pentobarbital sodium $\left(30 \mu \mathrm{g} \cdot \mathrm{g}^{-1}\right.$ i.p. body weight, Nembutal; Sanofi Sante b. v., Maassluis, The Netherlands), placed on a heating pad $\left(37^{\circ} \mathrm{C}\right)$ and an indwelling catheter was inserted in the right jugular vein as described by others [10]. Blood samples were collected on citrate $\left(3 \mathrm{mg} \cdot \mathrm{ml}^{-1}\right.$ final concentration) from the tail tip every 7.5 to $15 \mathrm{~min}$. Citrate was used instead of heparin to avoid activating the lipoprotein lipase which could influence lipolysis in blood. To prevent intravascular volume depletion and anaemia, an equivalent amount $(1 \mathrm{ml})$ of citrated $\left(3 \mathrm{mg} \cdot \mathrm{ml}^{-1}\right)$ fresh whole blood, obtained by heart puncture from littermates of the experimental animals, was infused at a constant rate throughout the $120 \mathrm{~min}$ infusion period.

Basal conditions. In one series of experiments $(n=5$ for each group), $3-{ }^{3} \mathrm{H}$-glucose (Amersham, Buckinghamshire, UK) was given as a prime $(4.7 \mu \mathrm{Ci})$-continuous $\left(0.15 \mu \mathrm{Ci} \cdot \mathrm{min}^{-1}\right)$ infusion and in another series of experiments $9,10-{ }^{3} \mathrm{H}$-palmitic acid (Amersham, UK) was given as a prime $(4.7 \mu \mathrm{Ci})$-continuous $\left(0.15 \mu \mathrm{Ci} \cdot \mathrm{min}^{-1}\right)$ infusion. Isotopic steady state conditions were achieved within $30 \mathrm{~min}$ after the initiation of the tracer infusion. The experimental procedure has been described previously [11].

Hyperinsulinaemic, euglycaemic conditions. During the hyperinsulinaemic euglycaemic clamps ( $n=5$ for each group), insulin was given as a prime $\left(104 \mathrm{mU} \cdot \mathrm{kg}^{-1}\right)$-continuous $\left(6 \mathrm{mU} \cdot \mathrm{kg}^{-1} \cdot \mathrm{min}^{-1}\right)$ infusion and a variable infusion of a $25 \%$ D-glucose solution was started and adjusted every 7.5 to 15 min (after each plasma glucose analysis) to maintain the plasma glucose concentration at about $7 \mathrm{mmol} / \mathrm{l}$. In one series of experiments, ${ }^{3}{ }^{3} \mathrm{H}$-glucose (Amersham) was given as a prime $(4.7 \mu \mathrm{Ci})$-continuous $\left(0.15 \mu \mathrm{Ci} \cdot \mathrm{min}^{-1}\right)$ infusion and in another series of experiments 9,10-3H-palmitic acid (Amersham) was given as a prime $(4.7 \mu \mathrm{Ci})$-continuous $(0.15 \mu \mathrm{Ci}$. $\mathrm{min}^{-1}$ ) infusion. Isotopic steady state conditions were achieved within $30 \mathrm{~min}$ after initiating the tracer infusion. The experimental procedure has been described previously [11].

Tissue collection. At the end of the hyperinsulinaemic clamp studies with $3-{ }^{3} \mathrm{H}$-glucose infusion, the abdomen of the mice was quickly opened, and the liver was freeze clamped in situ. Within $30 \mathrm{~s}$, rectus abdominal and gastrocnemius muscles as well as perirenal and epididymal fat were freeze clamped with aluminium tongs precooled in liquid nitrogen. All tissue samples were kept frozen at $-80^{\circ} \mathrm{C}$ until analysis. The procedure has been described previously [11-13].

\section{Blood pressure and heart rate}

To record the mean arterial pressure and heart rate, APOC1 transgenic $(n=5)$ and control $(n=6)$ mice were fasted for $6 \mathrm{~h}$ and anesthetized with pentobarbital sodium $\left(30 \mu \mathrm{g} \cdot \mathrm{g}^{-1}\right.$ i.p. body weight, Nembutal; Sanofi Sante, Maassluis, The Netherlands), placed on a heating pad $\left(37^{\circ} \mathrm{C}\right)$ and an indwelling catheter was inserted in the left carotid artery. The experimental procedure was done as described by others [14]. The arterial catheter was attached to a pressure transducer (Statham $\mathrm{P} 23 \mathrm{Db}$ ) which was connected to a blood pressure processor (Hellige, Freiburg, Germany) and a chart recorder (Gould 2400). After a $30 \mathrm{~min}$ stabilization period, haemodynamic 
Table 1. Body weights, plasma insulin and metabolite concentrations under basal and hyperinsulinaemic euglycaemic conditions in control and APOC1 transgenic mice

\begin{tabular}{|c|c|c|c|c|}
\hline \multirow[t]{2}{*}{ Metabolic Parameters } & \multicolumn{2}{|c|}{ Basal Conditions } & \multicolumn{2}{|c|}{ Hyperinsulinaemic euglycaemic conditions } \\
\hline & Control & APOC1 & Control & APOC1 \\
\hline Body weight (g) & $28.0 \pm 1.9$ & $29.5 \pm 1.7$ & $27.2 \pm 1.0$ & $27.1 \pm 0.6$ \\
\hline Glucose (mmol/l) & $10.0 \pm 1.1$ & $7.0 \pm 1.0^{\mathrm{a}}$ & $7.5 \pm 0.5$ & $7.0 \pm 0.6$ \\
\hline $\mathrm{NEFA}(\mathrm{mmol} / \mathrm{l})$ & $0.9 \pm 0.1$ & $1.9 \pm 0.2^{\mathrm{a}}$ & $0.5 \pm 0.1$ & $1.3 \pm 0.3^{\mathrm{b}}$ \\
\hline Triglycerides (mmol/l) & $0.6 \pm 0.1$ & $9.1 \pm 2.3^{\mathrm{a}}$ & $0.4 \pm 0.1$ & $3.7 \pm 0.6^{b}$ \\
\hline Cholesterol $(\mathrm{mmol} / \mathrm{l})$ & $1.6 \pm 0.1$ & $7.0 \pm 1.2^{\mathrm{a}}$ & $1.3 \pm 0.1$ & $2.8 \pm 0.4^{\mathrm{b}}$ \\
\hline
\end{tabular}

${ }^{\mathrm{a}} p<0.05$ compared to control mice under basal conditions. ${ }^{\mathrm{b}} p<0.05$ compared to control mice under hyperinsulinaemic euglycaemic conditions

measurements were recorded for a period of $30 \mathrm{~min}$, as described previously [15].

\section{Plasma analytical procedures}

Plasma glucose concentrations were measured in duplicate by the glucose oxidase method on a Beckman glucose analyser II (Beckman Instruments, Fullerton, Calif., USA). Plasma insulin concentrations were measured by specific radioimmunoassays [11-13] using rat and porcine insulin standards (Rat insulin kit, Linco, St. Louis, Mo., USA). Concentrations of total plasma cholesterol and triglycerides (without measuring free glycerol) were measured using commercially available enzymatic kits 236691 (Boehringer Mannheim, Mannheim, Germany) and 337-B (GPO-Trinder kit; Sigma Chemical, St. Louis, Mo., USA) [1, 3]. Plasma NEFA concentrations were determined in blood samples which had been immediately centrifuged $\left(\right.$ at $1{ }^{\circ} \mathrm{C}$ ) after collection and stored at $-80^{\circ} \mathrm{C}$ with a NEFA-C kit (WAKO Chemicals, Neuss, Germany) [4]. Methods for measuring plasma $3-{ }^{3} \mathrm{H}$-glucose specific activity have been described previously [11-13]. Briefly, plasma proteins were precipitated by $\mathrm{Ba}(\mathrm{OH})_{2}$ and $\mathrm{ZnSO}_{4}$ (Somogyi procedure), and the supernatants evaporated to dryness at $55^{\circ} \mathrm{C}$ to eliminate ${ }^{3} \mathrm{H}_{2} \mathrm{O}$, reconstituted in $100 \mu$ l of water, mixed with $5 \mathrm{ml}$ of scintillation fluid and counted for $10 \mathrm{~min}$ in a beta-scintillation counter (LKB, Woerden, The Netherlands). To measure ${ }^{3} \mathrm{H}$-NEFA specific activity $10 \mu \mathrm{l}$ of plasma was extracted with $10 \mathrm{ml}$ of Dole's solution as described previously [16]. We isolated NEFA from the lipid phase using $0.02 \mathrm{~N} \mathrm{NaOH}$ and re-extracted it after acidification with heptane. The heptane extraction was repeated three times and more than $90 \%$ of the radioactivity was consistently recovered in the heptane phase. The extraction efficiency of $9,10-{ }^{3} \mathrm{H}$-palmitic acid was measured by adding a known amount of $9,10-{ }^{3} \mathrm{H}$-palmitic acid infusate to plasma samples, which underwent the procedure described above. Plasma ${ }^{3} \mathrm{H}_{2} \mathrm{O}$ radioactivity, for both the 3${ }^{3} \mathrm{H}$-glucose or 9,10- ${ }^{3} \mathrm{H}$-palmitic acid infusion studies, was calculated by subtracting the disintegrations per min in an aliquot of the Somogyi supernatant $\left(3-{ }^{3} \mathrm{H}\right.$-glucose infusion study) or of plasma $\left(9,10-{ }^{3} \mathrm{H}\right.$-palmitic acid infusion study) that had been evaporated to dryness from an unevaporated aliquot.

\section{Tissue analytical procedures}

The number of tritiated glucose counts in glycogen and the lipid fraction of muscle, adipose tissue and liver were measured as previously described [11-13]. Briefly, $50 \mathrm{mg}$ of tissue was homogenized in $0.5 \mathrm{ml}$ phosphate buffered saline (PBS).
Then $0.6 \mathrm{ml}$ of a chloroform-methanol solution $(1: 2, \mathrm{vol} / \mathrm{vol})$ was added and vortexed for $5 \mathrm{~min}$. Subsequently, $0.2 \mathrm{ml}$ of chloroform was added and vortexed for $5 \mathrm{~min}$ and then $0.2 \mathrm{ml}$ of water was added and vortexed for $5 \mathrm{~min}$. The samples were centrifuged for $10 \mathrm{~min}$ at $6000 \mathrm{rpm}$. The upper aqueous layer was separated from the lower lipid-containing chloroform layer. The chloroform fraction was evaporated to dryness and counted. Glycogen was added to the aqueous fraction ( $1 \%$ glycogen solution), absolute ethanol was added $(1: 5 \mathrm{vol} / \mathrm{vol})$, vortexed and stored overnight at $-20^{\circ} \mathrm{C}$. After centrifugation $(13000 \mathrm{rpm})$, the supernatant was removed and $1 \mathrm{ml}$ of absolute ethanol was added to the glycogen pellet, vortexed and stored overnight at $-20^{\circ} \mathrm{C}$. The latter procedure was repeated twice. The glycogen pellet was dissolved in aqua dest and counted.

\section{Calculations}

Whole body glucose uptake and hepatic glucose production. Steady state calculations were carried out during the last $60 \mathrm{~min}$ of $3-{ }^{3} \mathrm{H}$-glucose infusion. The theoretical background of the calculations has been described previously [11-13].

Whole body palmitic acid uptake. Calculations were carried out as described previously [16] and as described for the use of $3-{ }^{3} \mathrm{H}$-glucose [11-13]. We used ${ }^{3} \mathrm{H}$ label instead of ${ }^{14} \mathrm{C}$ Label $[17,18]$. Steady state calculations were carried out during the last $60 \mathrm{~min}$ of $9,10-{ }^{3} \mathrm{H}$-palmitic acid infusion.

Whole body glycolysis and whole body glucose storage. The rate of whole body glycolysis (generation of ${ }^{3} \mathrm{H}_{2} \mathrm{O}$ in plasma) was measured during the last $90 \mathrm{~min}$ of $3{ }^{3} \mathrm{H}$-glucose infusion. The rate of appearance of ${ }^{3} \mathrm{H}_{2} \mathrm{O}$ in plasma is linear from 30 to $120 \mathrm{~min}$. The theoretical background of the calculations has been described previously [11-13].

Whole body palmitic acid oxidation and whole body palmitic acid storage. Oxidation and storage of $9,10-{ }^{3} \mathrm{H}$-palmitic acid were measured as described for the use of $3-{ }^{3} \mathrm{H}$-glucose [11-13]. Plasma ${ }^{3} \mathrm{H}_{2} \mathrm{O}$ radioactivity was calculated by subtracting the dpm in an aliquot of plasma which had been evaporated to dryness from an unevaporated aliquot. The calculation of oxidation and storage of NEFA using 9,10- ${ }^{3} \mathrm{H}$-palmitic acid has been described before [17].

Skeletal muscle, adipose tissue and liver glycogen and lipid synthesis from plasma glucose. The rate of net glycogen or lipid synthesis was expressed as micromoles of glucose units in glycogen or lipid per kilogram (wet weight) of tissue per minute. 


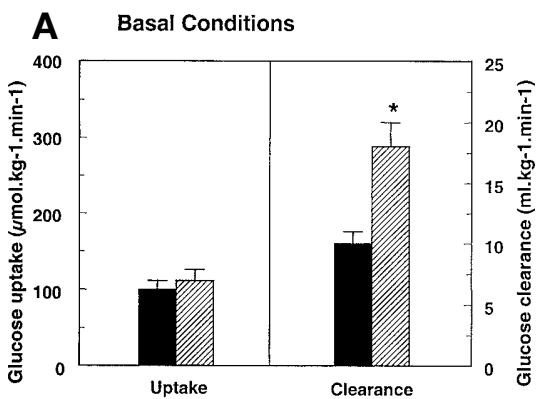

Fig. 1A, B. (A) Basal whole body glucose uptake (which equals hepatic glucose production in the basal state) and basal whole body glucose clearance in control $(\boldsymbol{\square})$ and hyperlipidaemic APOC1 transgenic (U) mice. $n=5$ mice per group. $* p<0.05$ versus control. (B) Insulin-mediated whole body glucose uptake, glycolysis, glucose storage and hepatic glucose production (HGP) in control ( $\boldsymbol{\square})$ and hyperlipidaemic APOC1 transgenic (ש) mice. $n=5$ mice per group. ${ }^{*} p<0.05$ versus control

The theoretical background of the calculations has been described previously [11-13].

\section{Statistics}

The unpaired two-tailed Student's $t$ test was used to define differences between APOC1 transgenic and wild-type (control) mice. We considered a $p$ value of $<0.05$ as significant. All data are presented as means \pm SEM.

\section{Results}

In vivo metabolism. The body weights, plasma insulin and metabolite concentrations under basal conditions (6 h fasting) in control and APOC1 transgenic mice

Fig. 2 A, B. (A) Basal whole body NEFA uptake and basal whole body NEFA clearance in control ( $\boldsymbol{\square})$ and hyperlipidaemic APOC1 transgenic (U) mice. $n=5$ mice per group. $* p<0.05$ versus control. (B) Insulin-mediated whole body NEFA uptake, NEFA oxidation and NEFA storage in control (ם) and hyperlipidaemic APOC1 transgenic (ש) mice. $n=5$ mice per group. $* p<0.05$ versus control

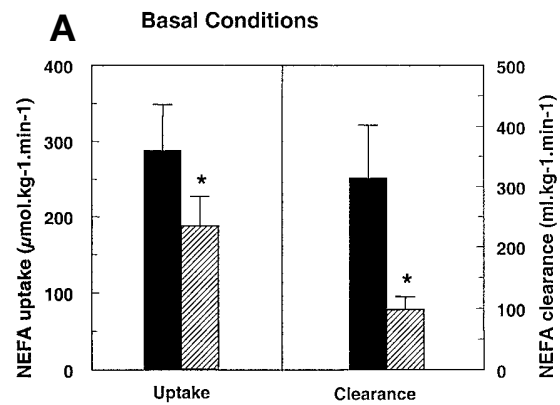

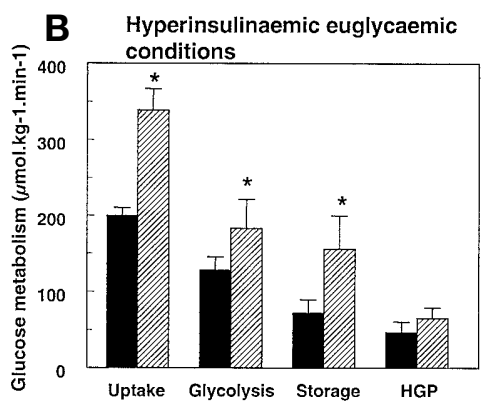

are shown in Table 1. Plasma insulin concentrations are not statistically different between control and APOC1 mice but the plasma concentrations of glucose are lower in APOC1 mice than in control mice. The plasma concentrations of NEFA, triglycerides and cholesterol are higher in APOC1 mice than in control mice. Under these basal conditions, whole body glucose metabolism was quantified with the use of $3-{ }^{3} \mathrm{H}$-glucose infusion (Fig. 1A) and whole body NEFA metabolism was quantified with the use of 9,10- ${ }^{3} \mathrm{H}$-palmitic acid infusion (Fig. 2A). Under basal conditions, whole body glucose uptake (which equals hepatic glucose production) is similar in APOC1 mice and control mice but this occurs for APOC1 mice at a plasma glucose concentration of $7.0 \pm 1.0 \mathrm{mmol} / \mathrm{l}$ (Table 1) and for control mice at a plasma glucose concentration of $10.0 \pm 1.1 \mathrm{mmol} / 1$ (Table 1). When mass action of plasma glucose is taken into account, as discussed in a previous paper [19], whole body glucose clearance is significantly higher in APOC1 mice compared to control (Fig.1A). Under basal conditions, whole body NEFA uptake is reduced in APOC1 compared to control mice (Fig. 2A) and this occurs for APOC1 mice at a plasma NEFA concentration of $1.9 \pm 0.2 \mathrm{mmol} / \mathrm{l}$ (Table 1 ) and for control mice at a plasma NEFA concentration of $0.9 \pm 0.1 \mathrm{mmol} / \mathrm{l}$ (Table 1). Despite the fact that plasma NEFA concentrations are high in APOC1 mice, the absolute rate of NEFA uptake is lower in APOC1 mice than in control mice. So, when mass action of plasma NEFA is taken into account, NEFA clearance is even lower in APOC1 mice than in control mice (Fig. 2A).

The body weights, plasma insulin and metabolite concentrations under hyperinsulinaemic euglycaemic conditions in control and APOC1 transgenic mice are

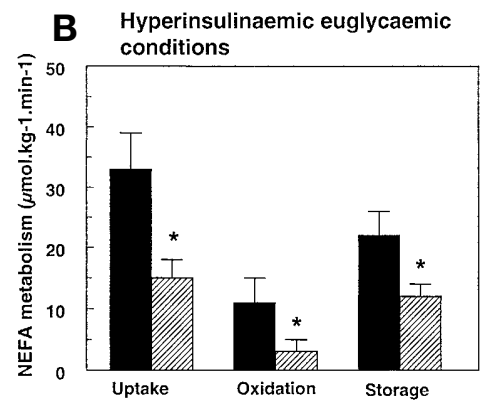



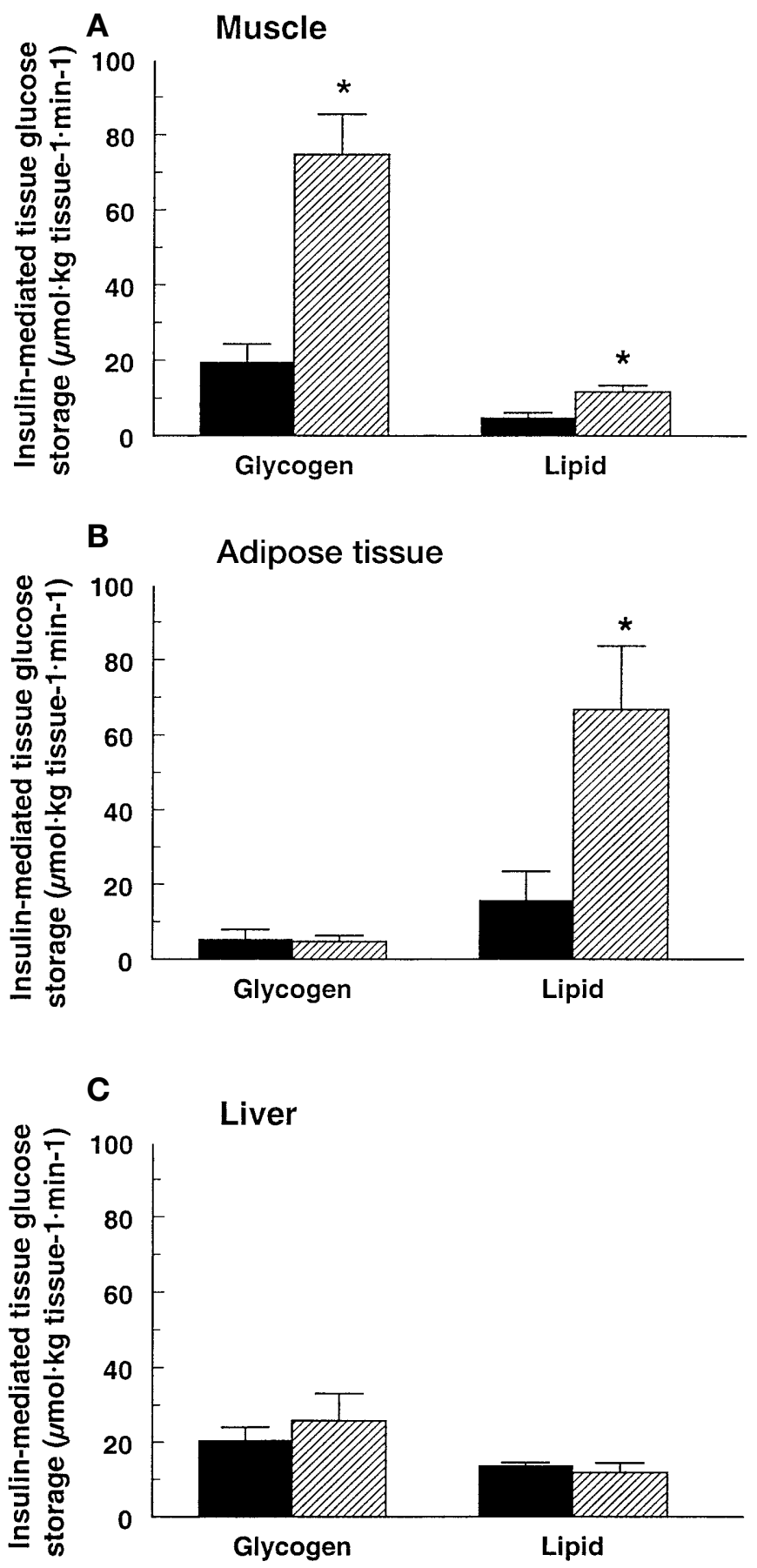

Fig. 3 A-C. Insulin-mediated rates of tissue specific net glycogen synthesis and de novo lipogenesis from plasma glucose in control $(\boldsymbol{\square}, n=4)$ and hyperlipidaemic APOC1 transgenic $(\mathbb{Z}, n=5)$ mice. $* p<0.05$ versus control

shown in Table 1. Plasma insulin and glucose concentrations are similar in control mice and APOC1 mice but the plasma concentrations of NEFA, triglycerides and cholesterol are higher in APOC1 mice than in control mice. Under these hyperinsulinaemic euglycaemic conditions, whole body glucose metabolism was measured with $3-{ }^{3} \mathrm{H}$-glucose infusion (Fig. 1B) and whole body NEFA metabolism was measured
Table 2. Body weight, mean arterial pressure and heart rate under basal conditions in control and APOC1 transgenic mice

\begin{tabular}{lcc}
\hline Metabolic Parameters & Control & APOC1 \\
\hline Body weight (g) & $29 \pm 1$ & $29 \pm 1$ \\
Blood pressure (mm Hg) & $85 \pm 3$ & $82 \pm 4$ \\
Heart rate (beats per min) & $484 \pm 11$ & $459 \pm 14$ \\
\hline
\end{tabular}

with 9,10- ${ }^{3} \mathrm{H}$-palmitic acid infusion (Fig. 2B). Under hyperinsulinaemic euglycaemic conditions, whole body glucose uptake, glycolysis and glucose storage are increased in APOC1 mice compared with control mice but hepatic glucose production is similar among mice (Fig. 1B). Under hyperinsulinaemic euglycaemic conditions, whole body NEFA uptake, NEFA oxidation and NEFA storage are lower in APOC1 than in control mice (Fig. 2B). This occurs for APOC1 mice at a plasma NEFA concentration of $1.3 \pm 0.3 \mathrm{mmol} / \mathrm{l}$ (Table 1) and for control mice at a plasma NEFA concentration of $0.5 \pm 0.1 \mathrm{mmol} / \mathrm{l}$ (Table 1). Despite the fact that plasma NEFA concentrations are high in APOC1 mice, the absolute rate of NEFA uptake, oxidation and storage are lower in APOC1 mice than in control mice. So, when the mass action of plasma NEFA is taken into account, whole body NEFA uptake, oxidation and storage would be reduced even further in APOC1 mice compared with control mice (data not shown). In general, when basal and insulin-mediated NEFA metabolism are compared, the plasma NEFA concentrations and the rates of NEFA uptake are reduced twofold to threefold. These phenomena have been described before and are in agreement with human studies [16].

Tissue collection. Under hyperinsulinaemic euglycaemic conditions, skeletal muscle $3-{ }^{3} \mathrm{H}$-glucose incorporation in glycogen and lipid increased in APOC1 mice compared with control mice (Fig. 3) but were similar for the liver among mice. Adipose tissue 3${ }^{3} \mathrm{H}$-glucose incorporation in lipid increased in APOC1 mice compared with control mice (Fig.3) but the incorporation in glycogen was similar in all mice.

Haemodynamic measurements. Mean arterial pressure and heart rate were similar among APOC1 transgenic and control mice (Table 2).

\section{Discussion}

ApoC1 overexpression in mice leads to the dysregulation of VLDL metabolism and thus to primary hyperlipidaemia including higher plasma concentrations of cholesterol, triglycerides and NEFA. We investigated whether a primary increase in plasma lipids, due to the overexpression of the human APOC1 gene, leads to the secondary development of insulin 
resistance for glucose metabolism and hypertension in transgenic mice. Our results indicate that primary hyperlipidaemia in itself does not necessarily lead to insulin resistance and high blood pressure.

The association between insulin resistance for glucose metabolism, hyperinsulinaemia, hyperlipidaemia and hypertension is often observed in obese patients or in patients with Type II (non-insulin-dependent) diabetes mellitus or in both and is called the insulin resistance syndrome $[7,8]$. The primary cause for the development of the insulin resistance syndrome is not known. One view is that insulin resistance for glucose metabolism, with compensatory hyperinsulinaemia, is the main abnormality leading to an increase in plasma triglycerides [6-8]. According to this view, insulin resistance and chronic hyperinsulinaemia enhance hepatic VLDL synthesis, leading to hypertriglyceridaemia [6-8]. Hyperinsulinaemia is thought to trigger hypertension by chronic activation of the sympathetic nervous system and by increasing sodium retention [6-9]. Another view [20, 21] is that NEFA, as a product of hypertriglyceridaemia or obesity or both, could be crucial in the development of the insulin-resistance syndrome or diabetes. Here, the most fundamental defect is in lipid metabolism, whereby higher plasma NEFA concentrations lead to an impairment in insulin-mediated glucose uptake and metabolism and compensatory hyperinsulinaemia. Apart from its effect of hyperinsulinaemia on haemodynamics, NEFA could enhance vasoconstriction and blood pressure [22].

To evaluate the latter view, we investigated whether insulin resistance for glucose metabolism and high blood pressure is present in hyperlipidaemic APOC1 transgenic mice.

Our study shows that primary hyperlipidaemia in APOC1 mice is neither associated with insulin resistance for glucose metabolism and hyperinsulinaemia nor with high blood pressure. On the contrary, both basal and insulin-mediated glucose metabolism were enhanced and blood pressure was normal in APOC1 mice. This indicates that increases in glucose metabolism are independent of insulin sensitivity and caused by an intrinsic change in metabolism. Therefore overexpression of human apoC1 protein in mice leads to hyperlipidaemia due to a primary impairment in lipid/NEFA metabolism which subsequently results in increased glucose metabolism.

A similar scenario was discussed in a previous paper [23] in which hypertriglyceridaemic APOC3 transgenic mice were studied. These mice showed normal whole body insulin-mediated glucose disposal. It was speculated that "insulin resistance will only be seen in situations in which the hypertriglyceridaemia is primarily due to increased VLDL-triglyceride secretion, not a prolonged VLDL residence time". In APOC3 transgenic mice hypertriglyceridaemia is thought to be primarily due to impaired li- polysis of VLDL-triglycerides, because apoC3 has been shown to be an effective modulator of lipoprotein lipase activity [24]. Increased concentrations of triglycerides upon APOC1 overexpression on the other hand have been shown to be mainly due to an impaired hepatic uptake of VLDL particles [3]. Thus in the case of APOC1 we hypothesize that NEFA's are liberated from VLDL-triglycerides but are not able to penetrate the tissues.

Therefore, the mechanism by which hyperlipidaemia develops is crucial to whether the insulin resistance syndrome develops or not. In obesity and Type II diabetes mellitus, hyperlipidaemia is usually caused by hepatic overproduction of VLDL, thus causing oversupply of lipids as metabolic fuel for body tissues. The latter would lead to insulin resistance for glucose metabolism.

By contrast, APOC1 transgenic mice are hyperlipidaemic due to, at least in part, reduced lipid clearance as our present study shows. Excess of apoC1 on the VLDL particle impairs hepatic uptake of plasma VLDL [3] and reduces whole body NEFA uptake, oxidation and storage (this study). Therefore, it seems that lipids remain in the circulation resulting in an undersupply of lipids as metabolic fuel for body tissues. In this case the Randle cycle is in operation which leads to increased (insulin-mediated) glucose metabolism to meet the increased intracellular energy demand. As shown in the present study, the undersupply of lipids to body tissues also increases de novo lipogenesis from plasma glucose in muscle and adipose tissue. The latter seems a compensatory mechanism for deficiency in intracellular lipid.

Our results suggest that the apoC1 protein, which is situated on the VLDL particle, is involved in the regulation of NEFA uptake from blood to body cells. Previously we have shown that, in addition to the inhibitory role of apoC1 on hepatic remnant uptake, overexpression of apoC1 affects lipid synthesis and adipose tissue formation [4]. The high amounts of apoC1 on VLDL in plasma of APOC1 transgenic mice could prevent the transport of NEFA from the circulation to the peripheral tissues. This agrees with the present observation that APOC1 transgenic mice show reduced whole body NEFA uptake, oxidation and storage in the face of increased plasma NEFA concentrations, indicating that the mass action of plasma NEFA cannot overcome the reduction in whole body NEFA uptake. Furthermore, it has been reported that mice deficient in VLDL-receptors also have reduced amounts of adipose tissue [25]. These findings suggest that the VLDL-receptors act as a docking protein for efficient triglyceride-rich lipoprotein lipolysis and the subsequent delivery of NEFA to peripheral tissues [26, 27]. Recently we showed that high concentrations of apoC1 on the VLDL particles result in defective binding of the VLDL particle to the VLDL-receptor in vivo [28]. The fact that apoC1 
acts on the VLDL particle to modulate whole body NEFA uptake suggests that both apoC1 and VLDL receptors are important factors in the regulation of NEFA transport from the blood to the tissues.

Finally, when hyperlipidaemia is caused by a reduction in lipid/NEFA clearance, as is the case in APOC1 transgenic mice, and not by increased hepatic lipid production, insulin resistance for glucose metabolism and high blood pressure are not likely to develop.

\section{References}

1. Jong MC, Dahlmans VEH, van Gorp PJJ et al. (1996) Both lipolysis and hepatic uptake of VLDL are impaired in transgenic mice coexpressing human apolipoprotein $\mathrm{E}^{*} 3$ Leiden and human apolipoprotein $\mathrm{C} 1$. Arterioscler Thromb Vasc Biol 16: 934-940

2. Schachter NS, Ebara T, Ramakrishnan R et al. (1996) Combined hyperlipidemia in transgenic mice overexpressing human apolipoprotein C1. J Clin Invest 98: 846-855

3. Jong MC, Dahlmans VEH, van Gorp PJJ et al. (1996) In the absence of the low density lipoprotein receptor, human apolipoprotein $\mathrm{C} 1$ overexpression in transgenic mice inhibits the hepatic uptake of very low density lipoproteins via a receptor-associated protein-sensitive pathway. J Clin Invest 98: 2259-2267

4. Jong MC, Gijbels MJJ, Dahlmans VEH et al. (1998) Hyperlipidemia and cutaneous abnormalities in transgenic mice overexpressing human apolipoprotein C1. J Clin Invest 101: 145-152

5. Randle PJ, Garland PB, Hales CN, Newsholme EA (1963) The glucose-fatty acid cycle: its role in insulin sensitivity and the metabolic disturbances of diabetes mellitus. Lancet i: $785-789$

6. Reaven GM (1991) Insulin resistance, hyperinsulinemia, hypertriglyceridemia and hypertension: parallels between human disease and rodent models. Diabetes Care 14: 195-202

7. DeFronzo RA, Ferrannini E (1991) Insulin resistance: a multifaceted syndrome responsible for NIDDM, obesity, hypertension, dyslipidemia, and atherosclerotic cardiovascular disease. Diabetes Care 14: 173-194

8. DeFronzo RA (1992) Insulin resistance, hyperinsulinemia, and coronary artery disease: a complex metabolic web. Coron Artery Dis 3: 11-25

9. Reaven GM, Lithell H, Landsberg L (1996) Hypertension and associated metabolic abnormalities: the role of insulin resistance and the sympathoadrenal system. N Engl J Med 334: 374-381

10. Marshall BA, Mueckler MM (1994) Differential effects of GLUT-1 or GLUT-4 overexpression on insulin responsiveness in transgenic mice. Am J Physiol 267: E738-E744

11. Koopmans SJ, Mandarino L, DeFronzo RA (1998) Time course of insulin action on tissue-specific intracellular glucose metabolism in conscious normal rats. Am J Physiol 274: E642-E650

12. Koopmans SJ, Leighton B, DeFronzo RA (1998) Neonatal de-afferentation of capsaicin-sensitive sensory nerves increases in vivo insulin sensitivity in conscious adult rats. Diabetologia 41: 813-820
13. Koopmans SJ, Kushwaha RS, DeFronzo RA (1999) Chronic physiologic hyperinsulinemia impairs suppression of plasma free fatty acids and increases de novo lipogenesis but does not cause dyslipidemia in conscious normal rats. Metabolism 48: 330-337

14. Samama P, Bond RA, Rockman HA, Milano CA, Lefkowitz RJ (1997) Ligand-induced overexpression of a constitutively active b2-adrenergic receptor. Pharmacological creation of a phenotype in transgenic mice. Proc Natl Acad Sci USA 94: 137-141

15. Koopmans SJ, Ohman L, Haywood JR, Mandarino LJ, DeFronzo RA (1997) Seven days of euglycemic hyperinsulinemia induces insulin resistance for glucose metabolism but not hypertension, elevated catecholamine levels or increased sodium retention in conscious normal rats. Diabetes 46: 1572-1578

16. Bonadonna RC, Groop LC, Zych K, Shank M, DeFronzo RA (1990) Dose-dependent effect of insulin on plasma free fatty acid turnover and oxidation in humans. Am J Physiol 259: E736-E750

17. Shimabukuro M, Koyama K, Chen G et al. (1997) Direct antidiabetic effect of leptin through triglyceride depletion of tissues. Proc Natl Acad Sci USA 94: 4637-4641

18. Sidossis LS, Stuart CA, Shulman GI, Lopaschuk GD, Wolfe RR (1996) Glucose plus insulin regulate fat oxidation by controlling the rate of fatty acid entry into the mitochondria. J Clin Invest 98: 2244-2250

19. Koopmans SJ, Maassen JA, Radder JK, Frölich M, Krans HMJ (1992) In vivo insulin responsiveness for glucose uptake at eu-and hyperglycemic levels in normal and diabetic rats. Biochim Biophys Acta 1115: 230-238

20. Boden G (1997) Role of fatty acids in the pathogenesis of insulin resistance and NIDDM. Diabetes 46: 3-10

21. McGarry JD (1992) What if Minkowski had been ageusic? An alternative angle on diabetes. Science 258: 1352

22. Stepniakowski KT, Lu G, Miller GD, Egan BM (1997) Fatty acids, not insulin, modulate a1-adrenergic reactivity in dorsal hands veins. Hypertension 30: 1150-1155

23. Reaven GM, Mondon CE, Chen IY-D, Breslow JL (1994) Hypertriglyceridemic mice transgenic for the human apolipoprotein C-III gene are neither insulin resistant nor hyperinsulinemic. J Lipid Res 35: 820-824

24. Ebara T, Ramakrishnan R, Steiner G, Shachter NS (1997) Chylomicronemia due to apolipoprotein CIII overexpression in apolipoprotein E-null mice. Apolipoprotein CIIIinduced hypertriglyceridemia is not mediated by effects on apolipoprotein E. J Clin Invest 99: 2672-2681

25. Frykman PK, Brown MS, Yamamoto Y, Goldstein JL, Herz J (1995) Normal plasma lipoproteins and fertility in gene-targeted mice homozygous for a disruption in the gene encoding very low density lipoprotein receptor. Proc Natl Acad Sci USA 92: 8453-8457

26. Yamamoto T, Takahashi S, Sakai J, Kawarabayasi Y (1993) The very low density lipoprotein receptor. Trends Cardiovasc Med 3: 144-148

27. Yamamoto T, Hoshino A, Takahashi S, Kawarabayasi Y, Iijima H, Sakai J (1995) The role of the very low density lipoprotein receptor in the metabolism of plasma lipoproteins containing ApoE. Ann NY Acad Sci 748: 217-225

28. Jong MC, Willems van Dijk K, Dahlmans VEH et al. (1999) Reversal of hyperlipidaemia in apolipoprotein C1 transgenic mice by adenovirus-mediated gene delivery of the low-density-lipoprotein receptor, but not by the verylow-density-lipoprotein receptor. Biochem J 338: 281-287 